\title{
PERFORMATIVIDAD EN LA ACADEMIA: UNA APROXIMACIÓN GENEALÓGICA AL CONCEPTO DE ESCRITURA PERFORMATIVA Y A SU USO EN EL RELATO DE LA INVESTIGACIÓN BASADA EN ARTES
}

\author{
Félix Gómez-Urda González \\ Universidad Complutense de Madrid. Dpto. de Periodismo y Nuevos Medios
}

\section{Resumen}

Este artículo es una aproximación epistemológica al concepto de escritura performativa, forma narrativa considerada aquí como tecnología para dar cuenta de los resultados de la Investigación Basada en Artes. El origen de este tipo de escritura lo situamos en las reflexiones sobre los enunciados performativos del filósofo John L. Austin y en las sucesivas réplicas y tensiones que sus ideas han encontrado en la filosofía, en la sociología, en la antropología y en el arte. El artículo ofrece una genealogía del concepto y sugiere respuestas a preguntas problemáticas en el ámbito de la investigación artística como ¿qué es la performatividad? o ¿qué elementos caracterizan la escritura performativa y qué papel desempeña en el contexto de las metodologías de Investigación Basada en Artes?

Palabras clave: ESCRITURA PERFORMATIVA; PERFORMATIVIDAD; INVESTIGACIÓN BASADA EN ARTE

\section{PERFORMATIVITY IN THE ACADEMY: A GENEALOGICAL APPROACH TO THE PERFORMATIVE WRITING CONCEPT AND ITS USE IN ARTISTIC RESEARCH`S STORYTELLING}

\section{Abstract}

This article is an epistemological approach to the concept of performative writing, a narrative form considered here as technology to account for the results of an Arts Based Research. The origin of this type of writing is placed in the reflections on the performative utterance of the philosopher John L. Austin and in the successive stress that his ideas have found in philosophy, sociology, anthropology and art. The article offers a genealogy of the concept and suggests answers to problematic questions in the field of artistic research such as, what is performativity? or what elements characterize performative writing and what role does it play in the context of Arts-Based Research methodologies?

\section{Keywords: PERFORMATIVE WRITING; PERFORMATIVITY; ARTISTIC RESEARCH`S STORYTELLING}

\footnotetext{
Gómez-Urda González, Félix. 2020. "Performatividad en la Academia: Una aproximación genealógica al concepto de escritura performativa y a su uso en el relato de la investigación basada en artes". AusArt 8 (1): 183-194. DOI: 10.1387/ausart.21546
}

\section{AUSART}




\section{ORÍGEN DE LOS CONCEPTOS}

La performatividad del lenguaje [performativity] fue el hallazgo fundamental de la teoría de los enunciados performativos de Austin. El filósofo británico vio la capacidad de algunas expresiones de convertirse en acciones y modificar la realidad o el entorno y, por lo tanto, de producir subjetividad. En el enfoque austiniano los enunciados performativos son 'actos de habla' y consecuentemente quedan confinados en el ámbito de la oralidad (Austin 1962). Siguiendo la tradición occidental Austin excluyó a la escritura de dicho espacio; la escritura no es acción, solamente usurpa la posición natural que el habla posee en relación con el pensamiento y las ideas: la literatura y en general todas las manifestaciones artísticas serían una práctica parasitaria del lenguaje. Jacques Derrida (1971) y Paul De Man (1980) impugnarán la teoría de los actos performativos de Austin, pero será Judith Butler (1989) quien para explicar sus ideas sobre la construcción de la identidad de género propondrá un nuevo desarrollo teórico de la teoría de los actos performativos y abrirá un nuevo espacio para el pensamiento y la acción queer.

El término 'perform"1 había surgido quinientos años antes del giro performativo, como primera conexión etimológica entre las ideas de 'terminación' y 'exhaustividad', durante el periodo de grandes transformaciones de la Europa del siglo XIV, cuando el trabajo artesanal y los gremios comenzaron a desplazarse hacia el concepto al que pronto se le daría el nombre de 'arte', un tipo de producción nacida en el Renacimiento. En el siglo XIX, 'performing' y 'performance' sirven como conceptos que denominan formas teatrales exhibidas en público. Finalmente, en los albores de la posmodernidad, se acuñará el término 'performative' para entender la fuerza y la naturaleza procesual de expresar, hacer, o pronunciar como formas de autoexpresión y realización. Después de cinco siglos de viaje la expresión 'acto performativo' adquiere un nuevo sentido: la performatividad no es un acto único, si no una repetición y un ritual que logra su efecto mediante su naturalización en el contexto de un cuerpo (Butler 1990). Entendido así, un cuerpo es, hasta cierto punto, una construcción, una mascarada con una duración temporal sostenida culturalmente. Butler ofrece una idea del género como espacio en donde las diferentes identidades pueden ser expresadas libremente. Butler recurre a la teatralidad y señala que la performatividad es el vehículo a través del cual se establecen los efectos ontológicos: la performatividad sería el modo discursivo mediante el cual se instalan los efectos ontológicos (Butler 1994). Efectivamente, la teoría de la performatividad de Butler reconoce el poder del Estado en los efectos ontológicos que este produce sobre los sujetos; el propio sujeto sería un efecto ontológico. 


\section{LA ESCRITURA PERFORMATIVA}

La escritura performativa (EP) es una tecnología representacional en la medida que sirve para elaborar el relato de los nuevos paradigmas epistemológicos en el arte y en las ciencias humanas vinculados a la teatralidad. Si toda escritura es performativa, en la medida en que esta se materializa en el acto mismo de su invención y de su enunciación (Pavis 2016), dicha característica resulta aún más evidente en el caso de la dramaturgia, cuyos textos presentan enunciados que son sugerencias para su puesta en escena. Este enfoque dramatúrgico alcanza también al ámbito de la investigación académica basada en artes, en tanto la EP forma parte de las metodologías cualitativas de investigación en la ciencias sociales, el arte y las humanidades, al mismo nivel que otras tecnologías basadas en la producción de narrativas: la entrevista, la investigación-acción, las historias de vida o la autoetnografía. Amparada en el concepto de 'texto semiótico' la EP se relaciona con disciplinas como la danza, la literatura, la música, las artes visuales, el teatro o la perfomance, por citar las más claramente representacionales. La EP es por lo tanto una tecnología dinámica de representación, válida como método de análisis e interpretación de una 'actuación', representación estética o representación cultural, y también para dar cuenta de los resultados de una investigación cuya forma narrativa dependería del objeto del que se está discutiendo; se trata de (re) constituir este objeto en el acto de la escritura (Phelan 1997). En ese proceso de reconstitución la fuerza afectiva (y efectiva) del acontecimiento (artístico), la descarga de los afectos (y efectos) del investigador y su reacción directa ante el acontecimiento se ofrecen como parte de los resultados.

La EP es una representación generada por la observación del objeto investigado, un objeto que puede haber desaparecido debido a su carácter efímero y sólo puede ser reconstituido mediante la propia escritura o texto semiótico. Este acto de escritura reproduce lo que no se puede ofrecer como una declaración o una descripción neutral. Usando aquí los términos de la teoría de los performativos de Austin, podríamos decir que se trata de un acto performativo (que produce una acción al ser enunciado) y no un constatativo (que se limita a describir un estado de cosas). La EP asume la posición del investigador mediante estrategias autorales que definen un estilo propio con valor artístico, en relación con el objeto de arte que está siendo comentado. Se trata de explicar la obra de arte como un trabajo procesual, conceptual y discursivo, con un enfoque performativo que atiende al paradigma de la teatralidad es una idea de la cultura como proceso antes que como resultado. 
Esta tecnología apela al concepto de huella corporal que pervive en el observador y del que se da cuenta a través de la escritura; se trata de descubrir el rastro de la escritura, el efecto del juego de la observación participante en el cuerpo (Pavis 2016). Así, la EP se ha desarrollado al paso de la evolución de la subjetividad en las últimas décadas del siglo XX (Pollock 1998); sus características atienden a lo relacional y es evocadora, encarnada y consecuente (Madison 1998, 2005; Spry 2011); una escritura corporeizada, evocativa y material que pretende el efecto de resonancia mediante una clara reverberación citacional (Pelias 1999, 2007). La escritura actúa como método para revivir el acontecimiento y dar cuenta de una actuación.

Si consideramos que un proceso investigativo es en sí mismo una actuación sobre uno o varios objetos observados, la narración de esa investigación sería la reconstrucción de un proceso que ha sido atravesado por (y que ha atravesado a) el investigador y que ha atravesado su propio cuerpo, o por un grupo de investigadores y sus respectivos cuerpos; ¿qué es un grupo de investigación basado en arte si no un cuerpo formado por cuerpos? El objeto de investigación es recreado para que su 'narración' resulte eficaz, por rigurosa, comprensible y atractiva a los lectores/espectadores destinatarios de las pesquisas. Los resultados de la investigación tendrán que ser decodificados de nuevo por este receptor, que a menudo recibe un material textual con importantes carencias narrativas, en ocasiones en pro de una ingente cantidad de datos cuantitativos. La EP cobra especial relevancia porque revela la corporeidad como un aspecto más de la experiencia; evalúa además su importancia estética, política y moral, lo cual exige la aplicación de toda una serie de mediaciones entre el objeto artístico investigado, la investigación considerada como obra en proceso y la audiencia que la recibe. Dichas mediaciones son formales, pero también históricas, culturales, ideológicas y socioeconómicas y dan cuenta de un modelo estético (y experimental) del mundo que se quiere presentar al público.

La EP da cuenta de este proceso de un modo evocativo, no mimético, opera metafóricamente para hacer presente la ausencia y poner al lector en contacto con los objetos investigados: memoria, placer, sensaciones, imaginaciones, afectos, visiones y otras características propias de las formas narrativas actúan en el relato. Es metonímica, una representación autoconsciente, parcial o incompleta, que emerge de la diferencia entre el símbolo lingüístico y la cosa que debe representar. Permite por tanto la subjetividad al observar un compromiso dinámico en la relación entre el investigador, los objetos de la investigación y los receptores de esta. Atraviesa para ello diversos relatos, 
teorías, textos, intertextos y esferas de la práctica: opera en los intersticios de la escritura y la actuación alimentada por los discursos de la textualidad. La EP cita universos en los que la ritualidad, la repetición y la reiteración son estrategias discursivas; presenta escrituras y reescrituras, tanto la repetición de formas discursivas dadas como la propia escritura representada, en donde se expone la fragilidad de la identidad, la historia y la cultura constituidas como rituales recurrentes. Una escritura para la producción de sentido que desborda la lógica de los sistemas normativos. Una escritura consecuente que retoma la performatividad en el lenguaje destinada a sostener una diferencia: hacer que las cosas ocurran.

Si la escritura es capaz de construir sentido y significado, quizás sea admisible inferir que esos significados sean a su vez capaces de constituir subjetividad $y$, por lo tanto, nuevas identidades. La EP no es por tanto un género o una forma fija, como sus modelos textuales pudieran sugerir, si no una manera de describir lo que 'hace' una buena escritura. Ahora bien, la buena escritura en su totalidad no tiene porqué ser performativa, ni todos los escritores deberían considerar performativo su trabajo. La performatividad describe una práctica fundamentalmente material que debe coadyuvar a mostrar mediante un relato los resultados de la investigación. Como la performance, sin embargo, es también una forma analítica de enmarcar y subrayar aspectos de la escritura y de la vida. Sin embargo, sostener la denominación 'escritura performativa' solo para establecer formas y significados sería minar su flexibilidad analítica y traicionar las posibilidades de la performatividad con las limitaciones de la referencialidad (Pollock 1998).

\section{SOBRE ESCRITURA Y EMANCIPACIÓN}

Efectivamente, la EP surge en un espacio donde colisionan lenguajes filosóficos, artísticos y políticos; un espacio liminal y fronterizo, vórtice de subjetividades susceptible de producir sentido y simbologías nuevas, pero también realidades distintas. La EP no es un asunto formal de estilo, en el sentido de los destellos de talento o del juego superficial que permiten los ejercicios de estilo, si no una práctica discursiva que trata de renovar los discursos de la textualidad. Plantea las preguntas sobre qué significan o no las palabras, el complejo problema de cómo significan las palabras, sin tener que limitar la respuesta a tales preguntas a la reiteración de formas sociales, históricas y 
textuales. El concepto remite a un tipo de escritura 'efectiva', que se forma en el acto de escribir/hacer. Una escritura que se refleja en su propia forma, en la representación de sí misma. Los modos que marcan la superficie de la escritura superan la propia forma del signo escrito y muestran su eficacia al servicio de una construcción esencialmente performativa, una estructura que conforma el texto como un sistema dinámico. La escritura no se refiere por lo tanto solo a su capacidad de registro y posibilidades representacionales, si no al ámbito de la materialidad de sus acciones (Cornago 2005). El estatus de la palabra escrita es, en realidad, un regreso a sus orígenes performativos: la escritura adquiere una autonomía funcional que la redime de la función representacional, a la que la retórica moderna, olvidando su dimensión performativa y finalidad oral primigenia (actio), la había subordinado.

Los fines de la EP son pedagógicos y artísticos y, por lo tanto, políticos. El objetivo es crear en el investigador, en el artista y en el lector/espectador receptor de la obra, transformaciones, adhesiones o cambios significativos mediante la instalación de unos efectos predeterminados que tienen la capacidad de producir conocimiento nuevo en la narración que da cuenta de la investigación. El enfoque dramatúrgico, que reconstruye la investigación y da cuenta performativamente de las fases por las que atravesó, junto a un necesario rigor académico, permitirá considerar la investigación como una práctica artística que utiliza la escritura como tecnología para dar cuenta de los hallazgos de dicha investigación. Tal y como sucede en la autoetnografía, la EP requiere una disposición especial en el investigador; este debe observarse mientras observa, debe cuestionarse lo que piensa y cree, y deberá desafiar las fronteras de la representación: tendrá que preguntarse una y otra vez si ha penetrado de forma suficiente en las capas de sus propias defensas, temores e inseguridades, tantas veces como su proyecto de investigación requiera (Jones, Adams \& Ellis 2013). La EP se sitúa por consiguiente en la disrupción de lo ficcional y de lo factual, en la aporía entre lo constatable y lo performativo. Se trata de un modo de escritura como representación de realidades creadas, a su vez, mediante la propia escritura. ¿Qué es la realidad si no una gran invención llena de convenciones?

En la tercera década del siglo XXI, la escritura permanece como instrumento fundamental del lenguaje para instalar un determinado estado de cosas y, a la vez, como tecnología para subvertir el statu quo mediante la potencia performativa del propio discurso escrito. Es en este sentido que la democracia radical avala la necesidad de contar con un número mayor de escritores capaces de generar textos con los que producir sentido (Giroux 2005). Esta cuestión 
problematiza la idea de la escritura como técnica artística, fuera del alcance de la mayoría, por lo que se podría dar la paradoja de que los más preparados para la escritura no fueran capaces, u optaran por mantenerse al margen, de representar el papel de los ciudadanos dentro de una cultura democrática. No se trata por lo tanto de traducir una realidad fuera de sí misma si no, más precisamente, de permitir el surgimiento de nuevas realidades (Trinh 1989). Así, la escritura se presenta como forma constitutiva de las democracias no realizadas.

Si en El maestro ignorante (Ranciere 1987) reflexionaba sobre la brutalidad que hay en toda explicación, ese supuesto funciona igualmente en su argumentación sobre la emancipación de la mirada en relación con el espectador. Esa falta de saber se sostiene por la oposición entre la pasividad de la mirada, posición alejada de la verdad, y el hecho de actuar. Se trata de trasladar el presupuesto de igualdad entre artista e investigador y, podríamos decir, entre el investigador y el receptor de la investigación. El investigador, como el espectador, debe ser activo: observa, selecciona, compara e interpreta, y compone, así, su propio poema, tal como lo hacen a su manera actores o dramaturgos, directores teatrales, bailarines o performistas (Rancière 2010, 9-28). A diferencia del esquema en el que tanto el pedagogo como el artista tienen un saber que transfieren al alumno o espectador, se propone aquí una disociación entre lo que el artista transmite y lo que el investigador/espectador construye. Esta acción emancipatoria se corresponde con la capacidad que tenemos como individuos de traducir a nuestro lenguaje (escritura en sentido amplio) lo que percibimos, de vincularlo con nuestra propia aventura intelectual. En la capacidad de asociación reside la posibilidad de emancipación de cada individuo como espectador; todo espectador es de por si actor de su propia historia.

\section{ESTUDIO DE CASO: E AGORA? LEMBRA-ME2, ESCRITURA DOCUMENTAL PERFORMATIVA}

La metodología aplicada sobre el análisis del objeto se realiza mediante un enfoque performativo: la acción de los cuerpos de los protagonistas adquiere un estatus narrativo, al mismo nivel que la propia escritura, es decir, la performatividad es efectivamente un aspecto básico para el ejercicio de auto-representación que se produce en el texto debido a que intervienen en su construcción magnitudes performativas que, más allá de las cuestiones estructurales y 
técnicas, responden a criterios artísticos y por lo tanto tienen un fin estético y unos objetivos políticos.

La intencionalidad artística se pone en escena mediante la teatralización de lo cotidiano a través de la escritura dramática, cuya creación se basa en el lenguaje poético. En paralelo, el relato se estructura con enunciados y actos performativos asociados a la escritura lírica que son materializados corporalmente. El documento resultante es, como se ha dicho antes, un ejercicio de auto-representación basado en la interpretación. La estética que arrostra la obra es producto de su realización escénica: una gran performance en la que la actuación de los protagonistas está medida y calculada; se presentan situaciones 'recreadas'3 que confieren al texto un altísimo grado de verosimilitud, precisamente por la exhibición honesta de los elementos que constituyen el dispositivo de creación y que dan sentido y otorgan significados a los rituales que resultan de la integración de dichos elementos en la vida presente y en la recuperación de la memoria de los actantes.

En la materialización de esta puesta en escena intervienen, en primera instancia, los elementos básicos que constituyen la performance: escritura/texto/acción, actantes, escenario y realización/dirección. La combinación de estos elementos dará lugar a diferentes formas plásticas y visuales, narrativas en definitiva, a las que se llega a través del restablecimiento del comportamiento/vida que se desea exponer a la mirada del lector/espectador, es decir, después de haber pensado y ensayado la acción que otorgará sentido al conjunto de la escritura/texto.

En este proceso confluirán, en el momento de la materialización y de la recepción, otros elementos que contribuirán a señalar sentido y significados al relato: banda sonora, edición, mezclas, exhibición y recepción de lectores/espectadores, sin cuyo concurso no es viable la realización escénica ni la posibilidad de transformación. En este último aspecto, es decir en la recepción del texto por parte del investigador, entra en juego el concepto expuesto anteriormente de "espectador emancipado", ese lector o lectora 'ideal' que no se conformará con un vistazo superficial del contenido de la investigación performativa, si no que buscará (se buscará) en las ideas y reflexiones expuestas, en el interior mismo de la escritura. No es posible hablar de una escritura de carácter performativo sin una lectura que posea esta misma cualidad. Esta es la base para la investigación performativa. 
Se ha señalado antes la conciencia política e ideológica que está presente en nuestro estudio de caso. Un ser humano - un artista en un ejercicio de performatividad narrativa - decide poner en juego su vida para la consecución de un objetivo, allí donde los conceptos de cuerpo, enfermedad y sexualidad adquieren una relevancia de primer orden: atraviesan el tiempo del relato, desde el pasado hasta el presente. Así, lo político aparece en los intersticios de lo corporal para reformular el eslogan 'lo personal es político' en la expresión, 'lo corporal es político'. Mediante la escritura se describe la naturaleza de una patología: asistimos a la lucha de un cuerpo precario, una ficción biopolítica. Es política la exhibición de la precariedad de una vida afectada por los virus del VIH y del VHC. Es política sin metáforas, aunque esta figura retórica esté muy presente en el texto de Pinto y permita al investigador disfrutar con la narración, acceder al interior de esa vida precaria. Si hay un concepto en Butler que viene a asumir nuevas funciones en nuevos campos y que se apropia de las funciones, hasta entonces desempeñadas por el concepto de lo humano, es el de 'vida precaria'. Como ha señalado Emma Ingala (2016, 85-6):

Frente a la idea de humanidad, el énfasis en la precariedad y la vulnerabilidad pone de manifiesto la preeminencia de la relación sobre la sustancia, e impide pensar lo humano como algo definible por un atributo esencial e individual, aunque pueda ser compartido. Lo humano no es una categoría autosuficiente, si no que se construye y sostiene sobre un tejido de relaciones que el concepto de "vida precaria" pone de manifiesto. La relacionalidad fundamental del ser humano entraña no la conexión entre dos sujetos previamente dados y autónomos, si no la formación de los sujetos humanos, su acceso a la existencia, a través de y en su dependencia de los otros.

Joaquim Pinto no ha escondido su precariedad. Aun cuando en la vida real es un ser humano que preserva su intimidad, como lo haríamos cualquiera de nosotros, él se ha expuesto públicamente de una manera absolutamente inédita hasta el momento. Ha compartido el sufrimiento de una manera explícita y estética; nos ha hecho partícipes, o cómplices, de una lucha, a muerte, contra la enfermedad.

El material textual esta impregnado de la calidad performativa a la que la voz en off nos traslada de manera poética: material verbal, escritura que cohesiona el relato; efectos de la palabra performativa que aparecen repetidamente para configurar el tono hipnótico y envolvente: 'tengo que creer para creer'; 'vivimos tiempos tristes', 'mi vida no tiene nada de particular', expresiones que 
caracterizan el estado de ánimo de Pinto. La sensación de pérdida de memoria, la desconcentración, el amor, la presencia constante de la muerte...

El combate contra los efectos devastadores de la enfermedad se alimenta de un extraordinario interés por el origen de su estado, desde una encarnación poética in crescendo muy cercana a la mística, que emparenta la narración con otras confesiones de naturaleza autobiográfica, pero cuya veracidad en este caso no resulta cuestionable, precisamente por el carácter de performance en directo del relato. Pinto entrega así un relato íntimo; nos invita a pasar a su ámbito más privado, a conocer su cuerpo desnudo, a ejercer de voyeur mientras su marido y él practican sexo. No hay ninguna frivolidad en la mostración del acto sexual, al contrario, es el epítome de la acción de mostrar y el colofón de un viaje corporal, el viaje de unos cuerpos en conflicto. Los agones dramáticos, las diferentes tramas que tejen la narración, conducen a reflexionar desde este espacio artístico sobre el momento que atraviesan, en los tiempos de la Covid19, las relaciones del individuo con el poder. Cuestiones sobre las que el relato establece un debate político alrededor de la visibilidad de los cuerpos enfermos, de las vidas precarias. Pinto abraza la escritura fílmica como una extensión performativa de su propio organismo. Su voz narradora, mezclada con imágenes antiguas, fotografías, filmaciones en Super $8 \mathrm{~mm}$ y otros formatos domésticos, producen y alimentan un efecto hipnótico que potencia las emociones que emergen de la lectura y visionado del texto. E agora? Lembra-me es un modelo de performativo que incluye características propias de otras modalidades documentales en su intenso metraje. Desde este punto de vista modal, el relato se construye en torno a tres ejes fundamentales: la auto-representación, la narratividad y la performance. Para conducirnos hasta el lugar en el que lo personal se lee en clave política, el cineasta que se autoexpone en el interior del film ha creado un acto performativo de magnitud dramática, un 'otro' de sí.

E agora? Lembra-me, con su construcción abiertamente poética, personal e íntima, reivindica los cuerpos, la sexualidad y la vida. Narrada en primerísima persona, el texto informa del aquí y ahora (pero también podríamos decir del 'alli' y del 'entonces') de un individuo que decide escribir - y exhibir públicamente - su vida mediante el lápiz y la cámara, en un espacio donde cuerpos y sexualidades adquieren una relevancia estética de primer orden: cuerpos en el espacio como personajes fantasmáticos que atraviesan el tiempo del relato, desde el pasado hasta el presente de la acción, y que forman parte de la historia del protagonista y de su propia supervivencia. Un ejercicio de 
performatividad que reclama una aproximación igualmente performativa para su estudio académico mediante el relato de la investigación basada en artes.

\section{Referencias bibliográficas}

Austin, John Langshaw. (1962) 1990. Cómo hacer cosas con las palabras. Genaro R. Carrió, trad. Barcelona: Paidós

Butler, Judith. (1990) 2001. El género en disputa : El feminismo y la subversión de la identidad. Traducción, Mónica Mansour \& Laura Manríquez. Barcelona: Paidós

— . 1994. "Gender as performance: An interview with Judith Butler".By Lynne Segal \& Peter Osborne. Radical Philosophy 67. https://www.radicalphilosophy.com/interview/judith-butler

Cornago Bernal, Óscar. 2005. Resistir en la era de los medios: Estrategias performativas en literatura, teatro, cine y televisión. Madrid: Editorial Iberoamericana

De Man, Paul. (1980) 1990. La resistencia a la teoría. Trad., Elena Elorriaga \& Oriol Francés. Madrid: Visor

Derrida, Jacques. (1972) 1994. "Firma, acontecimiento, contexto". En Márgenes de la filosofía, trad. de Carmen González Marín. Madrid: Cátedra

Giroux, Henry A. 2005. Estudios culturales, pedagogía crítica y democracia radical. Con un epílogo de Douglas Kellner; trad., Nestor Cabrera. Madrid: Editorial Popular

Ingala, Emma. 2016. "Cuerpos vulnerables y vidas precarias ¿Un retorno de lo humano en la filosofía política de Judith Butler?". "Filosofía y cuerpo desde el pensamiento greco-romano hasta la actualidad", Suplemento monográfico, Daimon 5

Jones, Amelia. 2014. "Performar, performatividad, performance y la política de la huella material". En Perform: How to do things with(out) words: [Cómo hacer cosas con [sin] palabra], Catálogo exposición Centro de Arte Dos de Mayo, 22 marzo-21 sept., Chantal Pontbriand, ed.; trads. David Sánchez et al., 58-87. Madrid: CA2M

Jones, Stacy Holman, Tony E. Adams \& Carolyn Ellis, eds. 2013. Handbook of autoethnography. New York: Taylor \& Francis

Madison, D. Soyini. 1998. "Performance, personal narratives, and the politics of possibilities". En The future of performance studies: Visions and revisions, Sheron J. Dailey, ed. Annandale, VA: National Communication Association

- . 2005. Critical ethnography: Methods, ethics, and performance. Thousand Oaks CA: Sage

Pavis, Patrice. 2016. The Routledge dictionary of performance and contemporary theatre. New York: Taylor \& Francis

Pelias, Ronald J. 2007. "Performative writing: The ethics of representation in form and body". En Ethical futures in qualitative research: Decolonizing the politics of knowledge, Norman K. Denzin \& Michael D. Giardina, editors. Walnut Creek CA: Left Coast

- . 1999. Writing performance: Poeticizing the researchers body. Carbondale IL: Southern Illinois University

Phelan, Peggy. 1997. Mourning sex: Performing public memories. London: Routledge

Pinto, Joaquim. 2013. E agora? Lembra-me. CRIM Produções, 165 min. https://www.filmin.es/ pelicula/e-agora-lembra-me 
Pollock, Della. 1998. "Performative writing". En The ends of performance, edited by Peggy Phelan \& Jill Lane, 73-103. New York: New York University

Rancière, Jacques. (1987) 2010. El maestro ignorante : Cinco lecciones sobre la emancipación intelectual. Traducción de Núria Estrach. Barcelona: Laertes

- . 2010. El espectador emancipado. Trad. de Ariel Dillon. Buenos Aires: Manantial

Spry, Tami. 2011. Body, paper, stage: Writing and performing autoethnography. Walnut Creek CA: Left Coast

Trinh, T. Minh-ha. 1989. Woman, native, other. Bloomington IN: Indiana University

\section{Notas}

${ }^{1}$ Una aproximación a la escritura performativa y a la performatividad debe pasar necesariamente por la problemática traducibilidad de los conceptos originales en los que se funda el término. En primer lugar, debemos tener en cuenta la traslación al español del verbo inglés 'to perform' y los conceptos que genera. La historiadora del arte y teórica estadounidense Amelia Jones (2014) ofrece la siguiente cadena de definiciones para los términos implicados: 'Perform' (to perform): hacer, hacer bien, entretener, del anglo-francés 'parfurmer', alteración de performer, parfurnir, de par-, per- (del latín 'per': totalmente) y 'furnir': completar. El primer uso conocido de este término se encuentra en el siglo XIV. Un siglo después aparece el término 'performance': ejecución de una acción; representar un personaje en una obra; la eficiencia con la que tiene lugar una acción, acepciones que han llegado hasta nuestros días. Austin acuña en 1955 el término 'performative', acto de hacer o representar, o relativo a, o constitutivo de, un arte (como el arte dramático) que implica la actuación del público; en lingüística, relativo a una expresión que sirve para efectuar una operación o que constituye la ejecución del acto específico en virtud de su declaración.

${ }^{2}$ E agora? Lembra-me, de Joaquim Pinto (CRIM Produções, 2013). Seleccionada por la Academia Portuguesa de las Artes y las Ciencias Cinematográficas para representar a Portugal como candidata al Óscar a la Mejor Película Extranjera en el año 2015.

${ }^{3}$ En inglés: 'reenacted', el término que utiliza Richard Schechner para referirse a las performances y a los rituales.

(Artículo recibido: 15-03-20; aceptado: 07-05-20) 